\title{
INOVASI INSTRUMEN SIT AND REACH BERBASIS DIGITAL TECHNOLOGY
}

\author{
Januar Agung Nugraha, Agus Rusdiana
}

Program Studi Ilmu Keolahragaan

Departemen Pendidikan Kesehatan dan Rekreasi

Fakultas Pendidikan Olahraga dan Kesehatan

Universitas Pendidikan Indonesia, Jl. Dr. Setiabudhi no. 229 Bandung 40154

Jawa Barat - Indonesia

Em@il: agungcreativity@gmail.com

\begin{abstract}
Abstrak
Penelitian ini bertujuan untuk membuat inovasi instrumen sit and reach berbasis digital technology. Penelitian ini menggunakan pendekatan metode penelitian dan pengembangan (Research and Development / R\&D). Instrumen yang dibuat oleh peneliti ini menggunakan rangkaian elektronika berbasis Microcontroller Atmel Atmega 328p. Instrumen ini menggunakan sensor putar yang bernama Potensiometer Logaritmik. Cara melakukan tes menggunakan instrumen ini yaitu diawali dengan memasang alat pada kaki kiri dan menempatkan titik sensor tepat pada sendi paha (hip joint). Setelah itu, sampel melakukan gerakan dengan menekukkan badan ke depan (mencium lutut), kemudian alat diukur sesuai sudut yang terbentuk. Menekuknya sudut pada instrumen tersebut, akan mengakibatan perputaran pada sensor yang telah terpasang. Instrumen ini menggunakan kabel sebagai penghubung untuk transfer data dari sensor ke microcontroller untuk diproses, dan menghasilkan output dalam LCD. Instrumen ini memiliki tingkat validitas yang tinggi setelah diuji dengan instrumen yang memiliki validitas sebelumnya. Reliabilitas instrumen ini memiliki tingkat reliabilitas yang sangat tinggi setalah diuji antara tes pertama dan tes kedua. Instrumen ini dalam pengoperasiannya masih membutuhkan asisten, yang diharapkan kedepan mampu berkembang lebih efektif dan efisien.
\end{abstract}

Kata kunci: Fleksibilitas otot, sit and reach, teknologi digital, ilmu keolahragaan.

\section{PENDAHULUAN}

Olahraga mulai menjadi gaya hidup bagi masyarakat Indonesia. Hingga tahun 2016 ini, semakin banyak sarana olahraga seperti GOR Futsal, Lapangan Bola Basket, Lapangan Bulu Tangkis, lokasi Car Free Day, dsb. Tentunya tempat-tempat tersebut setiap harinya selalu diisi aktifitas olahraga oleh masyarakat.

Hal tersebut tidak terlepas dari peranan teknologi pada zaman modern ini. Teknologi mampu mengembangkan olahraga di berbagai bidang. Salah satunya dalam bidang olahraga prestasi, teknologi mampu membuat estimasi volume program latihan, intensitas program latihan, dan rest dalam melaksanakan program latihan, sehingga perencanaan bisa lebih sesuai dengan hasil yang di dapatkan. Dalam olahraga prestasi, teknologi memiliki peranan yang sangat penting. Karena di beberapa negara maju, penerapan teknologi dalam olahraga prestasi sudah terlaksanakan cukup lama. Sedangkan, penerapan teknologi dalam olahraga di Indonesia cukup tertinggal jauh. Giri Wiarto (2015, hlm. 148) menyatakan bahwa "IPTEK 
berperan besar dalam mendongkrak prestasi olahraga sehingga diharapkan semua elemen keolahragaan di tanah air bisa menguasai dan mengimplementasikan sesuai cabang masingmasing".

Komponen kondisi fisik terdiri dari kekuatan, kecepatan, daya tahan, dan fleksibilitas. Keempat komponen tersebut tidak bisa dipisahkan satu dengan lainnya. Salah satu komponen kondisi fisik yang menjadi objek penelitian adalah fleksibilitas. Menurut Dikdik (2007) yang dikutip oleh Iman (2014, hlm. 79) "Kelentukan atau fleksibilitas adalah kemampuan gerak dalam ruang gerak sendi yang seluas-luasnya". Fleksibilitas merupakan komponen yang terkadang terlupakan oleh beberapa pelatih atau atlet. Padahal, salah satu manfaat fleksibilitas adalah mengurangi resiko cedera. Bahkan fleksibilitas mampu meningkatkan efisiensi seseorang dalam melakukan gerakan. Salah satu fleksibilitas yang sering diukur adalah fleksibilitas otot belakang (otot punggung dan hamstring) atau persendian yang terlibat adalah sendi tungkai (hip joint).

Instrumen fleksibilitas otot belakang yang sering digunakan yaitu Bench/Meja Sit and Reach dengan Sit and Reach Test. Ada juga yang mengukurnya dengan busur dan jangka secara manual.

Dalam kesempatan ini, peneliti mencoba mengembangkan instrumen fleksibilitas otot belakang. Peneliti berharap mampu mengembangkan instrumen yang lebih akurat dari sebelumnya sebagai upaya meningkatkan olahraga prestasi dengan bantuan teknologi. Adapun yang akan dikembangkan peneliti yaitu instrumen sit and reach berbasis digital technology.

Dilakukan penelitian ini yaitu untuk mengetahui cara kerja instrumen yang dikembangkan. Dan mengetahui tingkat validitas dan reliabilitas instrumen yang dikembangkan.

Alat dan tes yang baik harus memenuhi kriteria, beberapanya yaitu validitas, reliabilitas, dan objektivitas. Valid merupakan suatu kriteria penting yang harus dipenuhi oleh suatu alat ukur. Tes yang valid menurut Nurhasan dan Hasanudin (2007, hlm 35) "Tes yang mengukur apa yang hendak diukur. Suatu pengukuran dapat dikatakan valid, bila alat pengukuran atau tes benar-benar tepat untuk mengukur apa yang hendak diukur dan sesuai dengan gejala yang diukurnya". Sedangkan menurut Morrow (2010, hlm. 88) "Validity is the degree of truthfulness of a test score."

Untuk menguji kesesuaian alat ini dilakukan validitas kriteria. Suharsaputra (2014, hlm. 99) menyatakan bahwa "Validitas kriteria adalah validasi suatu instrumen dengan membandingkannya dengan instrumen lainnya yang sudah valid dan reliabel dengan cara mengkorelasikannya". Jadi validasi alat yang telah dikembangkan ini dilakukan dengan cara mengkorelasikan hasil tes fleksibilitas otot belakang menggunakan inovasi instrumen sit and reach berbasis digital technology dan alat ukur yang lama. Analisis menggunakan SPSS dengan koefisien korelasi bivariate.

Reliabilitas penting untuk mengukur keajegan suatu tes. Hal ini penting karena sebuah tes harus memiliki ketetapan baik dari segi pelaksanaan dan penilaian. Jika alat tersebut memiliki keajegan maka hasil dari pengukuran secara berulang-ulang akan menghasilkan data yang sama. Menurut Morrow (2010, hlm 88) "Reliability can also be described as accuracy, consistency, dependability, stability, and precision." Artinya suatu instrument tes yang reliable yaitu tes yang dapat menggambarkan akurasi, konsintensi, keandalan, stabilitas, dan ketepatan. Yang dinyatakan reliable yaitu tes tersebut dilakukan di tempat yang berbeda ataupun pada populasi yang berbeda dengan karakteristik yang tidak jauh berbeda maka hasilnya tidak akan jauh berbeda sehingga tes tersebut dapat diandalkan (reliable) dan jika tes tersebut diulangi dikemudian hari hasilnya harus menunjukan kekosistenan.

Untuk menguji reliabilitas alat ini dilakukan test-retest. Sugiyono (2012, hlm. 130) menyatakan "test-retest dilakukan dengan cara mencobakan instrumen beberapa kali pada responden lalu dikorelasikan". Jadi pengetesan 
dilakukan sebanyak dua kali setiap seminggu sekali kepada sampel. Hasil yang diperoleh dari data tersebut akan di uji korelasi menggunakan koefisien korelasi bivariate yaitu dengan tujuan mengukur keeratan hubungan antara dua variabel.

Objektifitas merupakan penilaian yang bersifat objektif, adil dan jujur. Menilai dengan apa adanya, sehingga hasil yang diperoleh memang hasil dari yang diharapkan. Menurut Lutan dan Suherman, (2000) "objektifitas ialah suatu tes didefinisikan sebagai derajat kesepakatan diantara beberapa orang pengetes. Suatu tes dikatakan objektif, jika terdapat kesaman skor yang diberikan oleh beberapa penilai". Sedangkan menurut Morrow (2010, hlm. 89) "Objectivity is a special kind of reliability."

\section{METODE}

Pada penelitian ini digunakan metode penelitian Research and Development (R\&D). Sugiyono (2012, hlm. 297) mengungkapkan bahwa yang dimaksud dengan metode Research and Development yaitu "Metode penelitian yang digunakan untuk menghasilkan produk tertentu dan menguji keefektifan produk tersebut".

Menurut Sugiyono (2012, hlm. 80) "Populasi adalah wilayah generalisasi yang terdiri atas: obyek/subyek yang mempunyai kualitas dan karakteristik tertentu yang ditetapkan oleh peneliti untuk dipelajari dan kemudian ditarik kesimpulannya". Dalam penelitian ini untuk uji coba alat melibatkan mahasiswa Ilmu Keolahragaan FPOK angkatan 2014 dengan jumlah 58 orang dalam populasinya.

Sampel menurut Sugiyono (2012, hlm. 81) "Sampel adalah bagian dari jumlah dan karakteristik yang dimiiki oleh populasi tersebut".Populasi yang digunakan pada penelitian ini yaitu Mahasiswa Ilmu Keolahragaan angkatan 2014. Simpel Random Sampling adalah teknik sampel yang digunakan pada penelitian tersebut. Sugiyono (2012, hlm. 82) menyatakan bahwa "Simple random sampling dikatakan simple (sederhana) karena pengambilan anggota sampel dari populasi dilakukan secara acak tanpa memperhatikan strata yang ada dalam populasi itu". Sampel penelitian yang diambil berjumlah 12 orang.

Instrumen penelitian pada peneliti ini bertujuan untuk mengetahui hasil uji validitas dan reliabilitas alat fleksibilitas yang telah dikembangkan. Validasi yang tepat yaitu dengan validitas kriteria. Suharsaputra (2014, hlm. 99) menyatakan bahwa "Validitas kriteria adalah validasi suatu instrumen dengan membandingkannya dengan instrumen lainnya yang sudah valid dan reliabel dengan cara mengkorelasikannya". Jadi validasi alat yang telah dikembangkan ini dilakukan dengan cara mengkorelasikan hasil tes menggunakan instrumen sit and reach sebelumnya dan instrument sit and reach berbasis digital technolgy yang akan dikembangkan peneliti. Analisis menggunakan SPSS dengan koefisien korelasi bivariate, untuk menguji reliabilitas alat menggunakan reliabilitas test-retest. Sugiyono (2012, hlm. 130) menyatakan "Test-retest dilakukan dengan cara mencobakan instrumen beberapa kali pada responden lalu dikorelasikan". Jadi pengetesan dilakukan sebanyak dua kali dengan sampel yang sama, setelah itu hasilnya dikorelasikan.

Prosedur penelitian yaitu berupa langkahlangkah yang dilakukan dalam penelitian. Langkah- langkah dalam penelitian research and development menurut Sugiyono (2012, hlm. 298) adalah dengan diawali potensi masalah, kedua pengumpulan data, ketiga desain produk, keempat validasi desain, kelima refisi desain, keenam uji coba produk, ketujuh refisi produk, kedelapan uji coba pemakaian, kesembilan refisi produk, kesepuluh produksi masal. Namun berdasarkan pertimbangan peneliti, ada beberapa tahapan yang tidak diperlukan atau perlu disederhanakan. Maka peneliti hanya mengadopsi beberapa saja dari 10 tahap yang disampaikan Sugiyono tersebut. Selain itu peneliti mencoba menyederhanakannya menjadi 7 tahapan. Adapun tahapan yang akan dilakukan peneliti adalah dengan diawali potensi masalah, kedua pengumpulan data, ketiga desain produk, keempat validasi dan perbaikan desain, kelima 
uji coba produk, keenam analisis data, ketujuh menyusun laporan.

\section{HASIL DAN PEMBAHASAN}

Produk Inovasi Instrumen Sit and Reach Berbasis Digital Technology. Tujuan utama dari penelitian yang dilakukan adalah membuat inovasi instrumen sit and reach berbasis digital technology. Alat ini berfungsi untuk mengukur fleksibilitas otot belakang seseorang dilihat dari perputaran sendi paha (hip joint). Setelah alat dipasang dan sensor diletakkan sesuai dengan poros hip joint masing-masing. Kemudian assisten mengukur sudut yang terbentuk, maka output berupa satuan derajat sudut akan muncul di layar LCD. Sensor rotasi yang digunakan pada alat ini dinamakan dengan sensor Potensiometer. Tentunya ada sistem yang mengatur agar alat ini bisa beroperasi. Di dalam alat ini terdapat microcontroller dengan jenis atmel atmega 328p, diletakkan tepat di dalam box LCD. Selain itu, alat ini diberi baterai dengan jenis battery 600mAh dan bisa diisi ulang langsung menggunakan charger tipe android. Dengan konsep portable instrument, maka alat ini memudahkan kita untuk suhaeefisien. Adapun alat yang telah dibuat yaitu sebagai berikut lengkap dengan komponen-komponen pendukungnya.

Cara kerja alat ini masih membutuhkan asisten untuk mengukur fleksibilitas seseorang. Diawali dari menghubungkan seluruh perangkat. Kemudian menyalakan LCD dengan menggeserkan saklar. Pasang alat pada orang yang akan diukur tingkat fleksibilitasnya. Lakukan sikap siap dengan duduk tegak. Pilih tombol "SET" pada layar. Kemudian orang yang dites mulai melakukan gerakan. Setelah maksimal, tunggu 3 detik kemudian asisten mengukur fleksibilitasnya. Kemudian dilanjutkan untuk pengulangan tes atau dilanjutkan pengetesan orang berikutnya. Data akan direkam/disimpan secara otomatis.

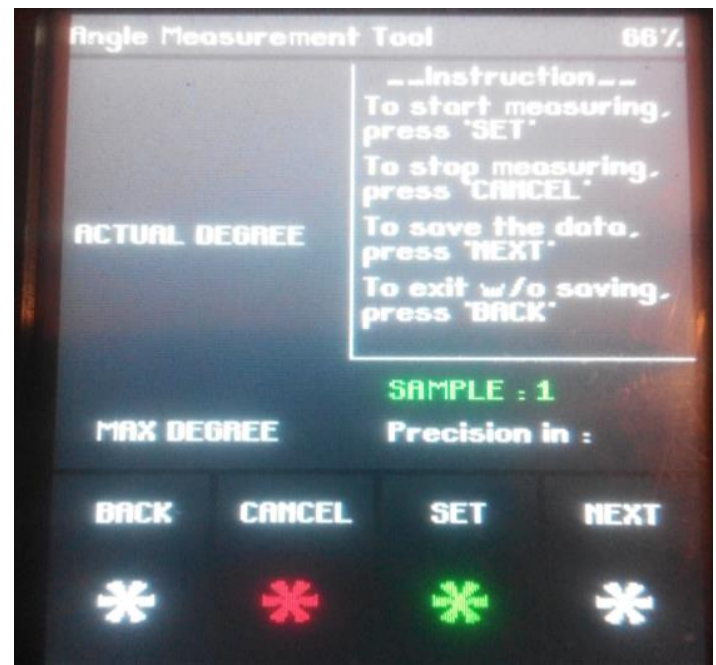

Gambar 1. Tampilan Layar LCD

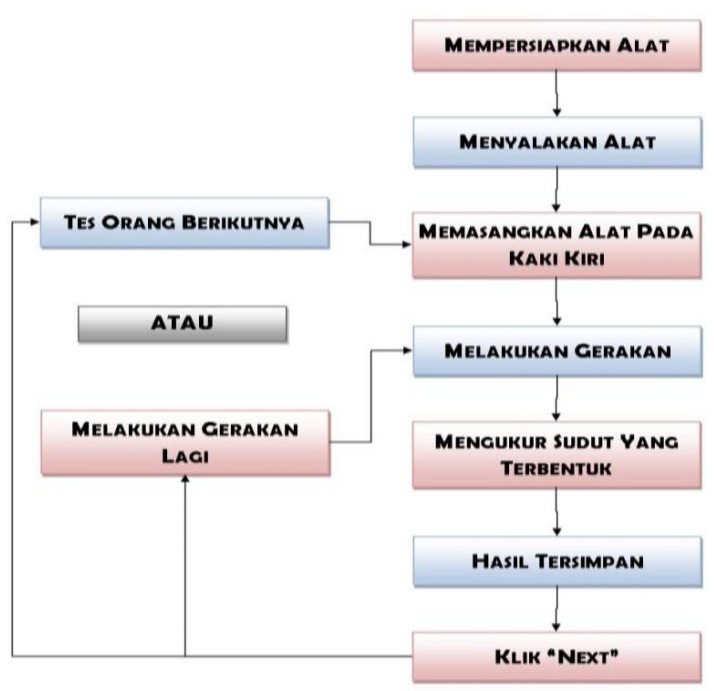

Gambar 2. Diagram Sistem Kerja Alat

\begin{tabular}{|c|c|c|c|c|c|c|c|}
\hline \multirow{2}{*}{$\begin{array}{c}\text { N } \\
\text { O }\end{array}$} & \multirow{2}{*}{ NAMA } & \multicolumn{3}{|c|}{ ALAT LAMA (cm) } & \multicolumn{3}{|c|}{ ALAT BARU $\left(^{\circ}\right)$} \\
\cline { 3 - 8 } & & Ke-1 & $\begin{array}{c}\text { Ke- } \\
2\end{array}$ & $\begin{array}{c}\text { Ke- } \\
3\end{array}$ & $\begin{array}{c}\text { Ke } \\
-1\end{array}$ & $\begin{array}{c}\text { Ke } \\
-2\end{array}$ & $\begin{array}{c}\text { Ke } \\
-3\end{array}$ \\
\hline 1 & $\begin{array}{c}\text { Ahmad } \\
\text { Jundi }\end{array}$ & 19,7 & $\begin{array}{c}21, \\
1\end{array}$ & $\begin{array}{c}19, \\
3\end{array}$ & 63 & 61 & 63 \\
\hline 2 & $\begin{array}{c}\text { Adi Ari } \\
\text { Putro }\end{array}$ & 24,4 & $\begin{array}{c}25, \\
9\end{array}$ & $\begin{array}{c}25, \\
1\end{array}$ & 53 & 52 & 54 \\
\hline 3 & $\begin{array}{c}\text { Fahmi } \\
\text { Destian }\end{array}$ & 17,4 & $\begin{array}{c}10, \\
1\end{array}$ & $\begin{array}{c}10, \\
7\end{array}$ & 65 & 67 & 65 \\
\hline 4 & $\begin{array}{c}\text { Handriana } \\
\text { Wijaksana }\end{array}$ & 11,3 & $\begin{array}{c}14, \\
4\end{array}$ & $\begin{array}{c}13, \\
3\end{array}$ & 65 & 63 & 64 \\
\hline 5 & $\begin{array}{c}\text { Hengki } \\
\text { Setiawan }\end{array}$ & 8,5 & 9,4 & $\begin{array}{c}10, \\
1\end{array}$ & 61 & 63 & 63 \\
\hline 6 & $\begin{array}{c}\text { Iqbal } \\
\text { Andiansya } \\
\text { h }\end{array}$ & 22,1 & $\begin{array}{c}22, \\
1\end{array}$ & $\begin{array}{c}22, \\
7\end{array}$ & 51 & 48 & 47 \\
\hline 7 & $\begin{array}{c}\text { Muhamma } \\
\text { d Renaldi }\end{array}$ & 20,4 & $\begin{array}{c}20, \\
9\end{array}$ & $\begin{array}{c}20, \\
7\end{array}$ & 55 & 54 & 54 \\
\hline 8 & $\begin{array}{c}\text { Muhamma } \\
\text { d Riffai }\end{array}$ & 19,3 & $\begin{array}{c}19, \\
5\end{array}$ & $\begin{array}{c}18, \\
4\end{array}$ & 60 & 59 & 58 \\
\hline 9 & $\begin{array}{c}\text { Muhamma } \\
\text { d Rijal }\end{array}$ & 19,8 & $\begin{array}{c}22, \\
3\end{array}$ & $\begin{array}{c}23, \\
7\end{array}$ & 49 & 47 & 46 \\
\hline & $\begin{array}{c}\text { Rangga } \\
\text { Kharisma }\end{array}$ & 17,0 & $\begin{array}{c}19, \\
2\end{array}$ & $\begin{array}{c}19, \\
4\end{array}$ & 54 & 51 & 50 \\
\hline
\end{tabular}




\begin{tabular}{|c|c|c|c|c|c|c|c|}
\hline \multirow{2}{*}{11} & $\begin{array}{c}\text { Ricky } \\
\text { Malik }\end{array}$ & 21,8 & $\begin{array}{c}23, \\
0\end{array}$ & $\begin{array}{c}24, \\
8\end{array}$ & 51 & 53 & 52 \\
\hline \multirow{2}{*}{12} & Riswan & 29,5 & $\begin{array}{c}28, \\
\text { Nur Fajrin }\end{array}$ & $\begin{array}{c}27, \\
8\end{array}$ & 48 & 47 & 47 \\
& & 8 & 8 & & \\
\hline
\end{tabular}

Tabel 1. Hasil Tes Fleksibilitas

\section{Uji Komparasi}

Berikutnya adalah melakukan uji komparasi. Uji komparasi dilakukan untuk mengetahui apakah terdapat perbedaan antara hasil tes menggunakan instrumen sit and reach yang dikembangkan dan hasil tes menggunakan instrumen yang lama. Adapun data hasil analisis statistik yang diperoleh adalah sebagai berikut:

\begin{tabular}{|c|c|c|c|}
\hline & Sig. & Keputusan & Kesimpulan \\
\hline Perbandingan & 0,00 & H0 ditolak & $\begin{array}{c}\text { Terdapat } \\
\text { perbedaan }\end{array}$ \\
\hline
\end{tabular}

Tabel 2. Uji Komparasi

Pada hasil data uji coba dan setelah diujikan menggunakan independent sample $t$ test memiliki nilai signifikansi 0,00 untuk hasil pengukuran menggunakan instrumen baru dan instrumen lama. Karena $\mathrm{p}<0,05$, maka H0 ditolak. Sehingga disimpulkan bahwa terdapat perbedaan yang signifikan antara hasil pengukuran menggunakan instrumen baru dan instrumen yang lama.

\section{Uji Validitas}

Sesuai dengan tujuan penelitian yaitu ingin mengetahui validitas atau tingkat keeratan hubungan antara instrumen sit and reach yang lama dengan instrumen sit and reach yang baru, analisis dilanjutkan dengan uji korelasi untuk menghitung koefisien korelasi antara dua variabel menggunakan koefisien korelasi bivariate. Adapun hasilnya sebagai berikut:

\begin{tabular}{|c|c|c|c|}
\hline Output & $\begin{array}{c}\text { Pearson } \\
\text { Correlation }\end{array}$ & Sig. & Keputusan \\
\hline Validitas & $-0,696^{*}$ & 0,12 & H0 ditolak \\
\hline \multicolumn{4}{|c}{ Tabel 3. Uji Validitas } \\
\hline
\end{tabular}

Setelah hasil data uji coba dan setelah diujikan menggunakan pearson correlation. Memiliki nilai signifikansi 0,012 antara hasil pengukuran menggunakan instrumen baru dan instrumen lama. Karena $\mathrm{p}<0,05$, maka H0 ditolak. Sehingga disimpulkan bahwa terdapat hubungan yang signifikan antara hasil pengukuran menggunakan instrumen baru dan instrumen yang lama.

\begin{tabular}{|c|c|}
\hline Korelasi & Tingkat hubungan \\
\hline $0-0,19$ & Sangat rendah \\
\hline $0.2-0.39$ & Rendah \\
\hline $0.4-0.59$ & Sedang \\
\hline $0.6-0.79$ & Tinggi \\
\hline $0.8-1$ & Sangat tinggi \\
\hline
\end{tabular}

Tabel 4. Tabel Koefisien Korelasi

Dengan nilai pearson correlation -0,696, maka hubungan yang terjadi memiliki tingkat hubungan yang tinggi dan hubungannya negatif. Maksudnya jika semakin besar hasil (cm) pengukuran menggunakan alat yang lama, maka akan semakin kecil hasil (derajat ${ }^{\circ}$ ) pengukuran menggunakan alat yang baru.

\section{Uji Reliabilitas}

Terakhir kita lakukan uji reliabilitas. Uji ini dilakukan untuk mengetahui konsistensi hasil pengukuran menggunakan instrumen baru pada tes ke-1 dan tes ke-2. Adapun hasil pengujiannya sebagai berikut:

\begin{tabular}{|c|c|c|c|}
\hline Output & $\begin{array}{c}\text { Pearson } \\
\text { Correlation }\end{array}$ & Sig. & Keputusan \\
\hline Reliabilitas & $0,984^{*}$ & 0,00 & H0 ditolak \\
\hline
\end{tabular}

Tabel 5. Tabel Reliabilitas

Setelah hasil data uji coba dan setelah diujikan menggunakan pearson correlation. Memiliki nilai signifikansi 0,00 antara hasil pengukuran menggunakan instrumen baru pada saat tes pertama dan tes kedua. Sehingga disimpulkan bahwa terdapat hubungan yang signifikan antara hasil pengukuran menggunakan instrumen baru pada saat tes pertama dan tes kedua.

Dengan nilai pearson correlation 0,984, maka hubungan yang terjadi memiliki tingkat hubungan yang sangat tinggi dan hubungannya positif. Maksudnya jika semakin besar hasil pengukuran tes pertama, maka akan semakin besar pula hasil pengukuran tes kedua.

\section{KESIMPULAN}

Simpulan 
Sistem kerja instrumen sit and reach ini dimulai dengan merakit semua bagian alat terlebih dahulu. Setelah tepasang seluruhnya, nyalakan saklar kemudian pasang alat pada kaki dengan mengikatkan tali yang ada agar stabil dengan bantuan asisten. Yakinkan bahwa posisi poros dan hip joint sudah tepat. Kemudian tekan tombol "SET" dan mulai melakukan gerakan menekuk badan semaksimal mungkin secara perlahan. Jika sudah maksimal, tahan 3 detik dan asisten mulai mengukur. Hasil akan tersimpan secara otomatis pada LCD. Selanjutnya tinggal menekan "NEXT" untuk melakukan tes berikutnya.

Hasil uji tes fleksibilitas menggunakan instrumen sit and reach berbasis digital technology ini terdapat perbedaan yang signifikan jika dibandingkan dengan tes fleksibilitas menggunakan alat yang sebelumnya. Mungkin ketimpangan nilai terlihat dikarenakan perbedaan satuan hasil pengetesan dari masing-masing instrumen. Instrumen yang sebelumnya memiliki hasil dengan satuan panjang $(\mathrm{cm})$, sedangkan alat yang dikembangkan memiliki hasil dengan satuan besaran sudut $\left(\right.$ derajat $\left./{ }^{\circ}\right)$.

Setelah dilakukan uji statistik terhadap data yang ada, didapatkan bahwa terdapat hubungan yang signifikan antara instrumen sit and reach berbasis digital technology dengan instrumen yang ada sebelumnya. Dengan nilai signifikansi 0,012 dan nilai pearson correlation -0,696. Sehingga instrumen ini bisa dikatakan memiliki validitas atau tingkat keeratan yang tinggi. Korelasi yang terjadi adalah korelasi negatif. Korelasi negative maksudnya adalah jika nilai tes salah satu instrumen besar, maka nilai tes instrumen yang lainnya akan kecil. Begitupun sebaliknya. Kemudian hasil uji reliabilitas alat ini memiliki nilai signifikansi 0,00 dan nilai pearson correlation 984 . Sehingga instrumen ini bisa dikatakan memiliki reliabilitas atau tingkat kestabilan yang sangat tinggi dari tes ke tes berikutnya. Korelasi yang terjadi adalah korelasi positif. Korelasi positif maksudnya adalah jika salah satu nilai variabel yang dibandingkan naik, maka nilai variabel yang membandingkannya akan naik pula, begitupun jika nilai salah satu variabel turun.

\section{Implikasi dan Rekomendasi}

Perlu adanya mahasiswa yang melanjutkan penelitian ini untuk dikembangkan lebih baik lagi dengan dukungan dan bantuan pihak terkait, khususnya Program Studi Ilmu Keolahragaan sebagai Prodi yang menjadi tempat naungan pengembangan keilmuan dalam bidang olahraga.

Peneliti berikutnya perlu mendesain ulang alat agar semakin efektif dan efisien. Disini peneliti berharap agar kedepan alat ini tidak membutuhkan asisten untuk membantu pengukuran.

Perlu adanya pengembangan oleh mahasiswa-mahasiswa yang lain, khususnya mahasiswa Ilmu Keolahragaan. Karena harapan peneliti terhadap penggunaan alat ini diakui di seluruh penjuru Indonesia bahkan dunia.

Perlu disamakan terlebih dahulu satuan nilai dari hasil pengukuran menggunakan inovasi instrumen sit and reach berbasis digital technology dan hasil pengukuran menggunakan instrumen yang sebelumnya, sebelum dilakukan uji statistik. Hal tersebut bertujuan agar penelitian yang dilakukan memiliki tingkat kepercayaan lebih, sehingga lebih dapat diakui lagi oleh para praktisi olahraga. 


\section{DAFTAR PUSTAKA}

Imanudin, Iman. (2014). Bahan ajar ilmu kepelatihan olahraga. Bandung: Universitas Pendidikan Indonesia.

R. Morrow, James., W. Jackson, Allen., G. Disch, James., and P. Mood, Dale. (2010). Measurement and evaluating in human performance. Edisi Kelima. United States of America: Human Kinetics.

Lutan, Rusli dan Suherman, Adang. (2000). Perencanaan pembelajaran penjaskes. Jakarta: Depdikbud.

Nurhasan dan Hasanudin. (2007). Tes dan pengukuran keolahragaan. Bandung: FPOK UPI. Sugiyono. (2012). Metode penelitian kuantitatif, kualitatif, dan R\&D. Bandung: Alfabeta.

Suharsaputra, Uhar. (2014). Metode penelitian kuantitatif, kualitatif, dan tindakan. Bandung: PT. Refika Aditama.

Wiarto, Giri. (2015). Olahraga dalam perspektif sosial, politik, ekonomi, IPTEK dan hiburan.Yogyakarta : Graha Ilmu 